\title{
Progress in extreme events forecasting, the case of the flood of November 1994 in Piedmont (Italy)
}

\author{
Enrico Ferrero ${ }^{1} \cdot{\text { Dino } \text { Zardi }^{2}}^{2}$ \\ Published online: 4 January 2021 \\ (C) The Author(s), under exclusive licence to Springer Nature Switzerland AG part of Springer Nature 2020
}

\section{Editorial}

The Piedmont Flood 1994 was a catastrophic event for the city of Alessandria that marked the life and development of the city for many years since. On 5 and 6 November 1994, the city of Alessandria, in particular the Orti district, as well as many surrounding villages in the province, such as San Michele, Casalbagliano, Solero and Castelceriolo, was invaded by the flooding of the Tanaro river. Similar major floods occurred in the same days in other areas of the Piedmont Region. Throughout the region, there were 70 victims (of which 14 in Alessandria), more than 2000 displaced persons, and about $\$ 3.41$ billion in damages and $\$ 14.5$ billion economic losses. This was ranked the 2nd costliest extreme event in Europe ever, as documented by the World Meteorological Organization (WMO Atlas, 2014).

Twenty-five years after, on 6 November 2019, the Department of Science and Technological Innovation of the University of Eastern Piedmont, in collaboration with Italian Association of Atmospheric Sciences and Meteorological (AISAM), organised a conference with the title '25 years after the 1994 Piedmont floods: progress made in predicting extreme events and open challenges'. The event offered an opportunity to define the progress made over the years in forecasting extreme events and what still needs to be done to forecast, prevent and avoid catastrophic events such as that of 1994. Since then, the Italian scientific community has developed increasingly advanced forecasting and protection tools. However, after 25 years, it is convenient to settle what remains to be done for better forecasting these evets in order to improve public safety. It was precisely in those years that the city of Alessandria saw the birth of University of Eastern Piedmont, which has always paid attention to environmental problems, also as a consequence of that event, which marked its development and growth up to the present.

\section{Enrico Ferrero}

enrico.ferrero@uniupo.it

1 Department of Science and Technological Innovation, University of Eastern Piedmont, Alessandria, Italy

2 Department of Civil, Environmental and Mechanical Engineering, University of Trento, Trento, Italy 
Speakers were invited from the main centres for weather forecasting and meteorological research bodies.

In the morning session, speakers provided a description of the event from the hydrological and meteorological points of view, the role of the Civil Protection for the flood events, the consequences concerning the health system in flood events, the progress of meteorological forecasting on a global scale and future prospects, the classification of extreme precipitation events in central-northern Italy and large-scale precursors and the role of the civil protection volunteering.

In the afternoon, the session focused on the comparison between the simulations of the flooding event made with today's models and those made with the models of that time. All the speakers were than invited to submit papers contributing to the present special issue. All the papers published here focus on the 1994 flood event simulated with today's modelling tools developed and applied by the various weather forecast centres. In particular, the papers contain respectively a test-bed of forecasting capabilities of the meteorological model suites developed at the Institute CNR-ISAC, the CIMA Research Foundation hydro-meteorological forecasting chain, a reforecasting of the Piedmont flood with a convection-permitting model (LAMMA), the reanalysis and reforecast using ERA5 and COSMO model (ARPAP), a post-processing of rainfall high-resolution simulation (NCAR), the dynamics of the Piedmont flood in the light of a recent classifications of extreme precipitations events (MI) and an ensemble-model reforecast of the event at the convection-permitting resolution (ARPAE).

Results presented in the papers clearly show how much progress has been made in weather forecasting systems, especially in recent years, both in terms of advanced alerting of intense events and in terms of higher resolution, accuracy and precision.

As an example of that, it may be interesting to mention an intense precipitation event occurred a few days before the conference in the region near Alessandria, on the 21 October, and later on the 23-24 November 2019, causing flooding episodes. Despite the relevant intensity, the impact on the population was largely less than in 1994, thanks to the progress made on the alert chain involving the Department of the National Civil Protection and the Regional Weather Services. 